\title{
The Eurozone's Equilibrium Real Exchange Rates
}

\author{
Antonin Rusek \\ Department of Economics, Susquehanna University, Selinsgrove, USA \\ Email: Rusek@susqu.edu
}

Received May 15, 2012; revised June 18, 2012; accepted June 25, 2012

\begin{abstract}
The equilibrium real exchange rate is the one of the key concepts in the macroeconomic and policy analysis. The importance of this concept yet increases in a currency union. In general, the real exchange rate misalignments are perceived to be the causes of the loss of a competitiveness, growth slowdowns and currency crises in cases of overvaluation, overheating and inflation in cases of undervaluation, sectoral misallocations of resources and global economic imbalances. In a case of a currency union the divergent dynamics of real effective exchange rates in the individual countries - both the actual and an equilibrium - will exacerbate both economic and political tensions (in addition to above mentioned problems) and may lead to the collapse of not only the monetary union per se but the underlying integration processes as well. This paper employs the estimation of the BEER (behavioral equilibrium exchange rate) for the seven Eurozone countries: Germany, France, Italy, Spain, Greece, Portugal and Ireland for the 1999:1-2011:3 period. The purpose is to compare the performance of the Eurozone "powerhouses" (Germany and France) with the countries on the Mediterranean littoral plus Ireland (so called "troubled periphery"). Those estimates are then used to calculate the degree of Euro's misalignment and the magnitude, persistence and the direction of dynamic tendencies within the Eurozone itself.
\end{abstract}

Keywords: Real Exchange Rate; Equilibrium; Misalignment

\section{Introduction}

The real exchange rate is among the most important categories in the both macroeconomic and the international economics analysis. The dynamics of the real exchange rate influences (and is in turn influenced by) the dynamics of both real and financial sectors of all economies. Empirically, the real exchange rate misalignments are perceived to be the causes of the loss of competitiveness, growth slowdowns and currency crises in cases of overvaluation, an overheating and inflation in cases of undervaluation, sectoral misallocations of resources and global economic imbalances.

In the case of a currency union which includes sovereign countries, the dynamics of the real exchange rate takes on an additional importance. The divergent dynamics of real effective exchange rates in the individual countries - both the actual and an equilibrium-will exacerbate both economic and political tensions and may lead to the collapse of not only the monetary union per se but the underlying integration processes as well.

The reason is that the members of a currency union loose both the monetary policy to influence domestic economic dynamic and the nominal exchange rate as a tool to influence unfavorable developments vis a vis the rest of the global economy.
That, indeed, places an increased burden on the remaining economic policy tools, namely the microeconomic policies (which encompass both regulations in general and labor markets policies) and the fiscal policy in all its aspects. But the use of the both microeconomic and fiscal policies to deal with unfavorable economic developments more often than not leads to an economic pain, which then results in the government unpopularity and the rising political and social tensions.

Under those circumstances individual governments attempt to influence the common monetary (and hence the exchange rate) policy in their favor. But because individual countries face different economic circumstances (and, in fact, may have governments with different economic preferences), attempts to influence the central monetary authority may (and will) lead to a rising tensions and disagreements between countries. This may eventually endanger the existence of the monetary union itself.

Whether a currency union is in the process of an increasing economic cohesion or an increasing divergence is, indeed, the empirical question. After all, in the entity like EMU (European Economic and Monetary Union, commonly called Eurozone) a degree of difference among member states is natural. It is the consequence of different historical, economic and political traditions, as they express themselves in differing legal systems, regulations, 
labor markets, social welfare and economic policy institutions. Removing those differences is a very long run process.

In the medium term the "cohesion" processes are supposedly facilitated by the processes of removing the obstacles to the movement of goods and services and capital among the Eurozone (and EU) member nations, by the harmonization of the of the goods, services, capital and labor markets regulations among these states and by a harmonization of public taxes and public services (i.e. the fiscal policy area). And whereas a large progress was made here in 1990s, the process itself slowed down radically after the Euro introduction in 1999 (Tilford, [1]).

That raises the question: did the introduction of the common currency resulted in an increased cohesion among the Eurozone countries? Or did it lead to increasing divergences (as the discussion above hinted is certainly possible)?

Dynamics of the real exchange rates may indicate possible answers. Even if the nominal exchange rate is the same for all Eurozone participants, the real exchange rates may differ. The reasons are the differing dynamics of the unit labor costs in the individual countries and the different trade patterns generating different weights in the calculations of the "effective" real exchange rates.

However, one would assume that as the Eurozone cohesion increases (i.e. it gradually becomes single economic area) the real effective exchange rates should converge as well-or at least not to diverge. And this process should be observable not only for the actual real effective exchange rates, but, perhaps more importantly, for their "equilibrium" values as well.

The objective of this paper is to analyze the long term dynamics of the real exchange rates in the several individual Eurozone countries and to estimate their "equilibrium" values. It is today increasingly recognized that the diverging real exchange rates (i.e. the diverging competitiveness) between the Eurozone members are at the root of the current crisis. But the equilibrium real exchange rate dynamics during the common currency existence is seldom analyzed and compared, especially as far as the different groups of countries (and/or different areas within the Eurozone) are concerned. This paper aims to contribute to filling this gap.

Therefore, the questions this paper seeks to answer are:

1) Do the "equilibrium" real exchange rates for the "core" (represented here by Germany and France) and "periphery" (Greece, Italy, Spain, Portugal and Ireland) of the Eurozone converge or diverge?

2) Are the actual real exchange rates for the individual analyzed countries in the Eurozone overvalued or undervalued with respect to the individual countries equilibria?

The discussion is divided into six parts. The next part provides the basic overview of the "equilibrium" real exchange rate concepts and literature. The third part then provides the basic discussion of the McDonald's BEER (behavioral equilibrium exchange rate) concept, which is then used in the further analysis. Part four reports econometric results which are then discussed in the part five. Part six concludes.

\section{2. "Equilibrium" Real Effective Exchange Rate: Modeling Concepts and Literature}

A misaligned real exchange rate is commonly thought of to be the one of the main reasons for economic disequilibria. However, it is obvious that the notion of "misalignment" of the real exchange rate requires the idea of the "equilibrium" real exchange rate.

But the latter one is not a simple concept, because the real exchange rate affects not only a single market (or a single economic sector) but the multitude of markets and sectors - both real and financial.

But even if the "equilibrium" real effective exchange rate can be defined theoretically, the complexity of this concept generates difficulties in operationalizing the equilibrium real effective exchange rate notion for the purposes of the empirical estimation and study.

The current economic and econometric approaches generally follow one of the three basic analytical models developed in the economic literature. Chronologically first is the FEER (fundamental equilibrium exchange rate). The variants of this approach were applied for a variety of the real effective exchange rates involving a multitude of countries. (Examples of work in the FEER tradition are Baffles et al. [2], Bayoumi et al. [3], Cline and Williamson [4], Feyzioglu [5], Wren-Lewis [6], this approach is analyzed and compared to others by Siregar and Rajan, [7]).

This model is derived from the (rather standard) economic assumption that the equilibrium real effective exchange rate is the one which is compatible with both the internal and external equilibria.

In the empirical work, the small multi-equation macroeconomic model is specified and estimated using observed values of the relevant economic variables. Equilibrium real effective exchange rate is then calculated using presumed long term (equilibrium) values of the economic variables.

(That is why some call this approach an equilibrium calculation, not estimation.) The degree of the misalignment is then calculated by comparing the actual real effective exchange rate with its calculated equilibrium values.

This approach is critiqued in two areas. First, the use and the implied need to estimate that the multi-equation macroeconomic model introduces possible inconsistencies and hence biases into the values of estimated coefficients. This comes from the fact that the number of variables in even relatively small models is often large relative to the 
number of available observations. That makes the direct and consistent estimation of the multi-equation model unfeasible. Hence, the single equation estimations must be used, tying them together by methods like seemingly unrelated regressions and trying to restore the coefficient consistency with subsequent calibrations. This technique, even if necessary under circumstances (the lack of sufficiently long reliable data), casts a shadow over the "estimated" coefficients and hence over the reliability of the calculated equilibrium real effective exchange rate itself.

Second, the specifications of both internal and external equilibria are often controversial. This is less so as far as the internal equilibrium is concerned, where concepts as the output at its potential level or the NAIRU level of unemployment are generally accepted as the internal equilibrium indicators. But even here the things are sometime controversial, given the demographic and preference dynamic, changing the retirement age, changing work participation rates etc.

The specification of an external equilibrium is the more disputed subject. It is generally recognized that the assumption of a zero external balance in the medium term is rather unrealistic, given the both domestic savings investment nexus and the medium term fiscal nexus. In these circumstances the assumptions regarding the medium term "external equilibrium" contain a strong normative element, which then affects the calculation of the equilibrium real effective exchange rates.

NATREX (Natural real exchange rate) class of models, first elucidated by Jerome Stein [8], reflects an effort to address some of the perceived shortcomings of the FEER approach. Here the assumption of the internal equilibrium is preserved, usually approximated by the NAIRU concept. However, the external position is modeled as a dynamic interaction between the long term values of domestic savings and investments, which then determine the current account and hence the long term capital flows. Both long term dynamic of domestic savings and investments is determined by economic fundamentals (relative productivity, relative wealth, rate of return differentials etc). Short term and cyclical influences are excluded from the determination of the equilibrium real effective exchange rate. Due to its construction the NATREX model is stock flow consistent.

The real effective exchange rate determined by the NATREX class of models is sometimes described as "dynamic", in contrast to the equilibrium rate determined by FEER models. The reason is that in NATREX models the equilibrium rate changes, reflecting the long term dynamics of domestic savings and investments. It follows that in a very long run (a stationary state equilibrium) all agents will be satisfied with their asset positions. That implies that both gross and net capital flows will cease, hence domestic savings must equal to domestic invest- ments. Current account-i.e. the external position-is balanced. In this sense the strictly theoretical long term FEER equilibrium real effective exchange rate is the limit value for the NATREX equilibrium real effective exchange rate.

Given its complexity and the simultaneous equations structure, the estimation of the NATREX models runs into similar difficulties as FEER approaches. To avoid some of the problems, most of empirical research utilizing NATREX approach uses reduced form estimations. That of course raises both the question of a stability of estimated coefficients (given the long run dynamics of factors determining saving - investment nexus, the Lucas type critique is certainly possible) and value of fundamentals free of short term and cyclical variations. For the more detailed discussions of NATREX type of models and their estimations see Gandolfo and Felettigh [9], Siregar and Rajan [7], Stein [8,10].

Both FEER and NATREX approaches define the equilibrium real effective exchange rate as the one corresponding to some definition of the general macroeconomic equilibrium. In contrast, in the BEER (behavioral equilibrium exchange rate) approach the equilibrium rate is the one consistent with the prevailing level of economic fundamentals.

First specified by Clark and MacDonald [11], the BEER approach is derived from the basically simple assumption of a uncovered interest parity (the more detailed discussion of the BEER approach is provided in the next part). The result is the single equation suitable for the estimating purposes. This makes the BEER approach especially suitable for situations where we are faced with a relatively short time series, as is in the case of the subject of this paper. The works utilizing the BEER approach include Bouveret [12], Clark and MacDonald [11,13], Dias and MacDonald [14], Giannellis and Koukouritakis [15], MacDonald [16-18], Maeso-Fernandez et al. [19], Osbat et al. [20]. BEER, FEER and NATREX models are compared in Siregar and Rajan [7].

\section{The BEER Type of the Equilibrium Real Effective Exchange Rate Model}

Let us specify the uncovered interest parity in real terms as:

$$
E s_{t+1}-s_{t}=r_{t}-r_{t}^{*}
$$

where $s_{t}$ is the real exchange rate (which here is defined as a foreign currency per unit of the domestic currency times domestic to foreign price ratios-i.e. an increase in $\mathrm{S}_{\mathrm{t}}$ is an appreciation and vice versa). $\mathrm{Es}_{\mathrm{t}+1}$ is the expected future value of the real exchange rate. $E s_{t+1}-s_{t}$ is then the expected rate of depreciation of the real exchange rate $\mathrm{s}$ (assuming that (1) is in logs). $r_{t}-r_{t}{ }^{*}$ is the domestic to foreign interest rate differential, where $r$ is the domestic 
real interest rate (defined generally as a nominal interest rate minus the expected rate of inflation) and the $r^{*}$ is the "world" real interest rate.

We can rewrite (1) as

$$
\mathrm{s}_{\mathrm{t}}=\mathrm{Es}_{\mathrm{t}+1}-\left(\mathrm{r}_{\mathrm{t}}-\mathrm{r}_{\mathrm{t}}^{*}\right)
$$

that is, the real exchange rate is the function of its own expected value and the real interest rate differential.

The BEER approach assumes that the expected real exchange rate is the function of economic fundamentals only. That is:

$$
\mathrm{ES}_{\mathrm{t}+1}=\mathrm{f}\left(\mathrm{Z}_{\mathrm{t}}\right)
$$

where $Z_{t}$ is the vector of economic fundamentals characterizing an economy at the period $t$.

From the empirical standpoint, the actual real exchange rate $\mathrm{s}$ can be influenced not only by its expected value (i.e. the economic fundamentals) and the interest rate differential, but by a variety of other short term variables - some of them cyclical, some reflecting short term shocks - as well. Let as denote the vector of such variables as $A_{t}$ which influences the real exchange rate via some function $g\left(A_{t}\right)$.

By substituting (3) into (2) and adding $g\left(A_{t}\right)$, we get

$$
S_{t}=f\left(Z_{t}\right)-\left(r_{t}-r_{t}^{*}\right)+g\left(A_{t}\right)=F\left(Z_{t}, r_{t}-r_{t}^{*}, A_{t}\right)
$$

where $\mathrm{F}(\cdots)$ is a general functional form.

Expresion (4) is the general BEER formulation of the real exchange rate. From here the equilibrium real exchange rate can be defined as the function of the economic fundamentals only, where the fundamentals values $Z_{t}^{E}$ are cleared of the random short term influences and measurement errors. i.e. $\mathrm{Z}_{\mathrm{t}}^{\mathrm{E}}=\mathrm{Z}_{\mathrm{t}}-\varepsilon_{\mathrm{t}}$, where $\varepsilon_{\mathrm{t}}$ represents random and measurement errors and $\mathrm{E}\left(\varepsilon_{\mathrm{t}}\right)=0$.

The equilibrium real exchange rate than can be expressed as:

$$
\mathrm{s}_{\mathrm{t}}^{\mathrm{E}}=\mathrm{F}^{\mathrm{E}}\left(\mathrm{Z}_{\mathrm{t}}^{\mathrm{E}}, \mathrm{A}_{\mathrm{t}}^{\mathrm{E}}\right)
$$

where $s_{t}^{E}$ denotes the equilibrium real exchange rate.

Assuming that the variables in the expression (4) are cointegrated (i.e. the coefficients reflect the long run equilibrium relationships) then the relevant coefficients in (4) and (5) may be assumed to be the same. Hence the estimate of (4) can be used to calculate the equilibrium and the implicitly the misalignment of the real exchange rate from the expression (5).

To estimate (4), we need to specify the set of variables for vectors $Z_{t}$ and $A_{t}$. In the economic literature, the commonly used set of variables to represent the economic fundamentals (i.e. the vector $\mathrm{Z}_{\mathrm{t}}$ ) are the terms of trade (TOT), the relative price of traded to non-traded goods (TNT), the net foreign assets (NFA), productivity (PROD) and the current account (CU). (For the relevant literature see for example Clark and MacDonald [11], MacDonald [18], Maeso-Fernandez, Osbat and Schnatz [19], Siregar and Rajan, [7]).

It goes beyond the scope of this paper (which is primarily empirical) to discuss in detail this choice of variables. Interested reader is referred to the authors mentioned above for the detailed and thoroughly argued explanations.

But one should mention that this set of variables is based on the stok-flow consistent model of an open economy specified by Frankel and Mussa [21]. In general, those variables represent the fundamental characteristics of an economy like relative productivity and growth, international competitiveness and its changes, preferences of agents, domestic investments-savings nexus, a general fiscal stance etc. (again, an interested reader should consult the literature listed above for clear and consistent arguments).

The vector $A_{t}$ contains only one variable, namely the ratio of the share of the domestic public debt in GDP (DGDP). $A_{t}=D_{t}$.

This variable was originally specified by Clark and MacDonald (and subsequently used by others) as a measure of the risk premium. However, one may argue that in the context of the currency union where national governments are deprived of tools of monetary and nominal exchange rate policies, the fiscal policies are the ones primarily used as a countercyclical and counter outside shocks tools. And this certainly will be reflected in short term variations of the debt to GDP ratios.

Substituting the expressions for $Z_{t}$ and $A_{t}$ into (4), we get:

$s_{t}=F\left(\right.$ TOT $\left._{t}, \mathrm{TNT}_{t}, \mathrm{NFA}_{t}, \mathrm{PROD}_{t}, \mathrm{CU}_{t}, \mathrm{r}_{\mathrm{t}}-\mathrm{r}_{\mathrm{t}}^{*}, \mathrm{D}_{\mathrm{t}}\right)(6)$

By the same logic, (5) can be replaced by:

$$
s_{t}^{E}=F^{E}\left(\mathrm{TOT}_{t}^{E}, \mathrm{TNT}_{t}^{E}, \mathrm{NFA}_{t}^{\mathrm{E}}, \mathrm{PROD}_{t}^{\mathrm{E}}, \mathrm{CU}_{t}^{\mathrm{E}}, \mathrm{D}_{\mathrm{t}}^{\mathrm{E}}\right)(7)
$$

where $\mathrm{TOT}_{t}^{\mathrm{E}}, \mathrm{TNT}_{t}^{\mathrm{E}}, \mathrm{NFA}_{t}^{\mathrm{E}}, \mathrm{PROD}_{t}^{\mathrm{E}}$, and $\mathrm{CU}^{\mathrm{E}}$ are values representing the economic fundamentals minus their short term shock effects and measurement errors. $\mathrm{D}^{\mathrm{E}}$ is some "equilibrium" value of $\mathrm{D}_{\mathrm{t}}$.

In the following analysis (6) will be used to estimate the real effective exchange rate, whereas (7) (utilizing coefficients obtained by estimating (6) will be used to calculate the "equilibrium" real effective exchange rate.

\section{Estimation}

All variables were tested for unit roots and were found to be I(1). Hence the estimation equation is defined in first differences (denoted below by the Greek letter $\Delta$. No logarithmic transformation could be used because of some negative observation of levels in CU and $r-r^{*}$.) Hence, for the purposes of the estimation, the Equation (6) is 
expressed as follows:

$$
\begin{aligned}
\Delta \mathrm{s}_{\mathrm{t}}= & \alpha_{0}+\alpha_{1}^{*} \Delta \mathrm{TOT}_{\mathrm{t}}+\alpha_{2}^{*} \Delta \mathrm{TNT}_{\mathrm{t}}+\alpha_{3}^{*} \Delta \mathrm{NFA}_{\mathrm{t}} \\
& +\alpha_{4}^{*} \Delta\left(\mathrm{r}_{\mathrm{t}}-\mathrm{r}_{\mathrm{t}}^{*}\right)+\alpha_{5}^{*} \Delta \mathrm{CU}_{\mathrm{t}}+\alpha_{6}^{*} \Delta \mathrm{PROD}_{\mathrm{t}} \\
& +\alpha_{7}^{*} \Delta \mathrm{D}_{\mathrm{t}}+\varepsilon_{\mathrm{t}}
\end{aligned}
$$

where $\Delta s_{t}$ is the (first difference) of the real effective exchange rate (REER), $\Delta \mathrm{TOT}_{\mathrm{t}}$ is the first difference of terms of trade (defined here as prices of exports over prices of imports), $\Delta \mathrm{TNT}_{\mathrm{t}}$ is the first difference of the ratio of the producer to consumer price indexes (used here as the proxy for the tradeables to non-tradeables price ratio), $\triangle \mathrm{NFA}_{\mathrm{t}}$ is first difference of the ratio of net foreign assets to GDP (both in Euro terms), $\Delta\left(r_{t}-r_{t}^{*}\right)$ is the first difference real interest rate differential, $\Delta \mathrm{D}_{\mathrm{t}}$ is the first difference of the ratio of the share of the domestic public debt in GDP to the same share for the world and $\triangle \mathrm{PROD}_{\mathrm{t}}$ is the value for productivity, represented here by the first differences of the output per capita. $\varepsilon_{t}$ is the error tem. The REER's are reported by the Eurostat as the foreign currency per unit of domestic currency (Euro) times domestic over foreign unit labor costs indexes. Hence an increase in $s_{t}$ indicates a real appreciation and vice versa.

All data needed for the all estimates of (8) were obtained from the Eurostat for the period 1999:Q1 to 2011:Q3 -i.e. 47 observations. The cointegration approach pioneered by Johansen was applied, using CATS2 program in RATS software. Results for all 7 countries are reported in Table 1.

To calculate the "equilibrium" values, the relevant form of the expression (7) can be written as

$$
\begin{aligned}
\Delta \mathrm{s}_{\mathrm{t}}= & \alpha_{0}+\alpha_{1}^{*} \Delta \mathrm{TOT}_{\mathrm{t}}^{\mathrm{E}}+\alpha_{2}^{*} \Delta \mathrm{TNT}_{\mathrm{t}}^{\mathrm{E}}+\alpha_{3}^{*} \Delta \mathrm{NFA}_{\mathrm{t}}^{\mathrm{E}} \\
& +\alpha_{4}^{*} \Delta\left(\mathrm{r}_{\mathrm{t}}-\mathrm{r}_{\mathrm{t}}^{*}\right)+\alpha_{5}^{*} \Delta \mathrm{CU}_{\mathrm{t}}^{\mathrm{E}}+\alpha_{6}^{*} \Delta \mathrm{PROD}_{\mathrm{t}}^{\mathrm{E}} \\
& +\alpha_{7}^{*} \Delta \mathrm{D}_{\mathrm{t}}^{\mathrm{E}}+\varepsilon_{\mathrm{t}}
\end{aligned}
$$

where $\alpha_{\mathrm{i}}$ ( $\mathrm{i}=1$ to 7 ) are the estimated coefficients (from the estimation of Equation (8) and the superscript $E$ indicates the medium term "equilibrium" values of explanatory variables (excluding random effects and measurement errors). These were obtained by applying the HodrickPresscot filter.

Utilizing results from (9), the degrees of misalignment were calculated using the formula

Misalignment $=\left(\mathrm{s}_{\mathrm{t}} / \mathrm{s}_{\mathrm{t}}^{\mathrm{E}}\right)-1.0$. Those results are reported and discussed below.

Explanations: All coefficients are from the estimate of the Equation (8) by the Johansen cointegration technique, using CATS2 program in Rats. All variables which the exclusion test indicated should be included are reported, even if the t-test indicates that they may not be statisti-

\begin{tabular}{|c|c|c|c|c|c|c|c|c|}
\hline & Terms of Trade & $\begin{array}{l}\text { Tradeables to } \\
\text { Non-tradeables }\end{array}$ & $\begin{array}{l}\text { Current Account } \\
\text { to GDP Ratio }\end{array}$ & Interest Rate & $\begin{array}{c}\text { NFA to GDP } \\
\text { Ratio }\end{array}$ & $\begin{array}{c}\text { Productivity } \\
\text { (GDP per Capita) }\end{array}$ & $\begin{array}{l}\text { Public Debt to } \\
\text { GDP Ratio }\end{array}$ & Constant \\
\hline \multirow[t]{2}{*}{ Germany } & 0.934 & 2.086 & 6.232 & -10.134 & -0.096 & & & 0.888 \\
\hline & $(2.506)$ & $(2.902)$ & $(11.623)$ & $(4.700)$ & $(2.888)$ & & & $(2.090)$ \\
\hline \multirow[t]{2}{*}{ France } & 0.830 & & -23.172 & & -0.239 & & & -2.283 \\
\hline & $(2.659)$ & & $(27.729)$ & & (2.687) & & & $(2.301)$ \\
\hline \multirow[t]{2}{*}{ Italy } & 0.478 & 4.305) & & & -0.745 & & 1.265 & -0.303 \\
\hline & (1.984) & $(5.045)$ & & & (12.249) & & $(3.512)$ & (2.417) \\
\hline \multirow[t]{2}{*}{ Spain } & 0.428 & 1.878 & -0.784 & -2.238 & -0.135 & & -0.378 & -0.138 \\
\hline & $(4.242)$ & (7.986) & (5.094) & $(3.845)$ & (14.698) & & $(2.551)$ & $(2.601)$ \\
\hline \multirow[t]{2}{*}{ Greece } & -0.206 & -1.142 & -1.001 & & 0.290 & 10.365 & & 1.1773 \\
\hline & $(1.960)$ & $(4.852)$ & (13.916) & & (19.004) & (1.985) & & $(4.280)$ \\
\hline \multirow[t]{2}{*}{ Portugal } & & -1.137 & -0.985 & -1.641 & 0.155 & -22.468 & & 1.168 \\
\hline & & $(6.639)$ & (13.714) & (5.104) & $(14.855)$ & $(3.688)$ & & $(5.478)$ \\
\hline \multirow[t]{2}{*}{ Ireland } & & & & 5.783 & 0.035 & -41.888 & -1.977 & 3.794 \\
\hline & & & & $(6.371)$ & $(2.811)$ & (13.555) & (11.852) & (6.549) \\
\hline
\end{tabular}
cally significant. In contrast, if the exclusion test indicated that a variable is not a part of the cointegrated vector such a variable was excluded-hence no value is reported.

Table 1. Estimates for individual countries.

Numbers in parenthesis are the relevant t-statistics. 


\section{Results: What Do They Tell Us}

Real equilibrium exchange rates (REERs) for the seven Eurozone countries (Germany, Greece, Italy, Spain, France, Portugal, Ireland) are reported in the Figure 1(a). The corresponding equilibrium values (calculated using Equation (9) are then in the Figure 1(b).

The visual inspection of the Figure 1(a) indicates the well known dynamics of the rising discrepancies between the individual countries REERs. Interestingly enough, it appears that the individual equilibrium REERs converged for 5 countries (Germany, France, Italy, Spain and Portugal) by the beginning of 2007-i.e. just before the onset of current difficulties. But those rates subsequently diverged again. Ireland and Greece remained the outliers throughout the analyzed period.

The comparisons of the individual national REERs with the calculated equilibrium values are shown in the Figure 2. Figure 3 than shows the misalignment of the individual national REERs, calculated by the formula stated above.

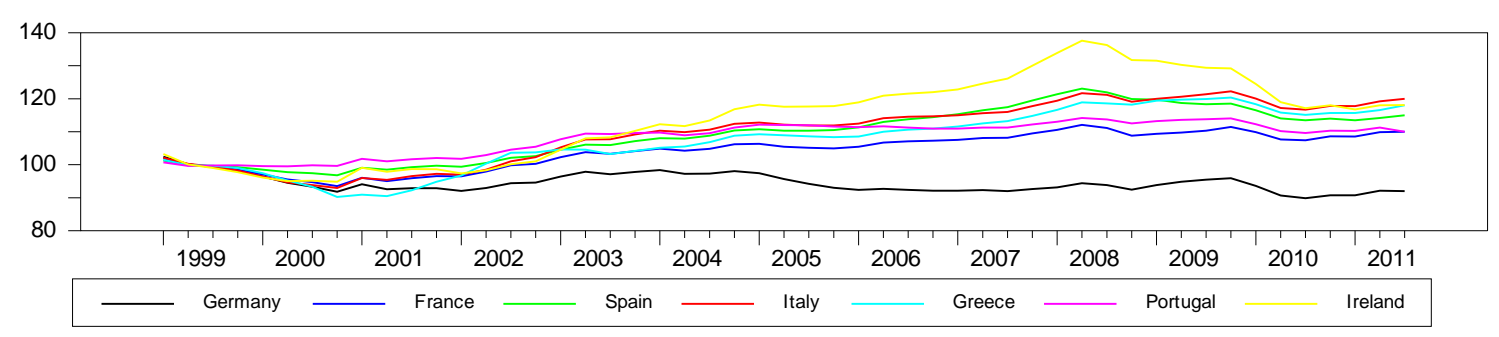

(a)

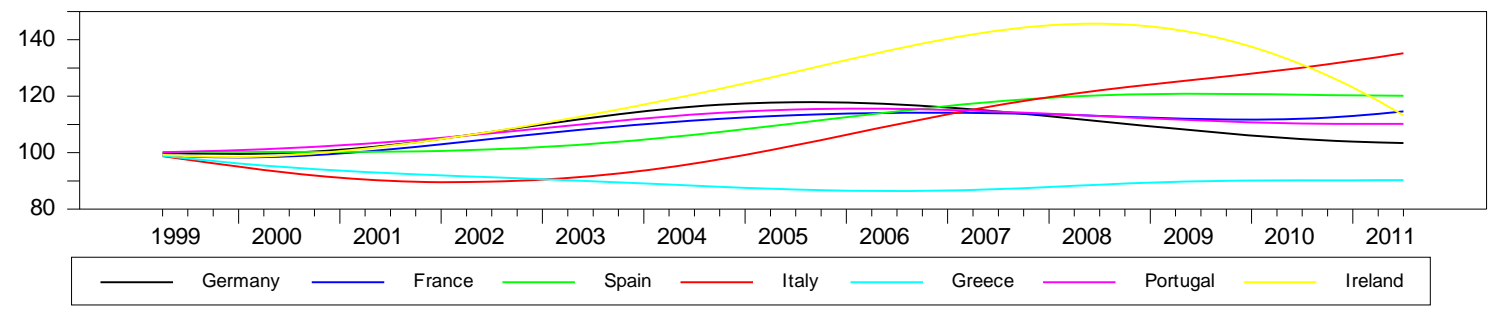

(b)

Figure 1. Real effective exchange rates: actual and equilibrium across countries. (a) Real effective exchange rates: 1999:12011:3; (b) Equilibrium real effective exchange rates: 1999:1-2011:3.
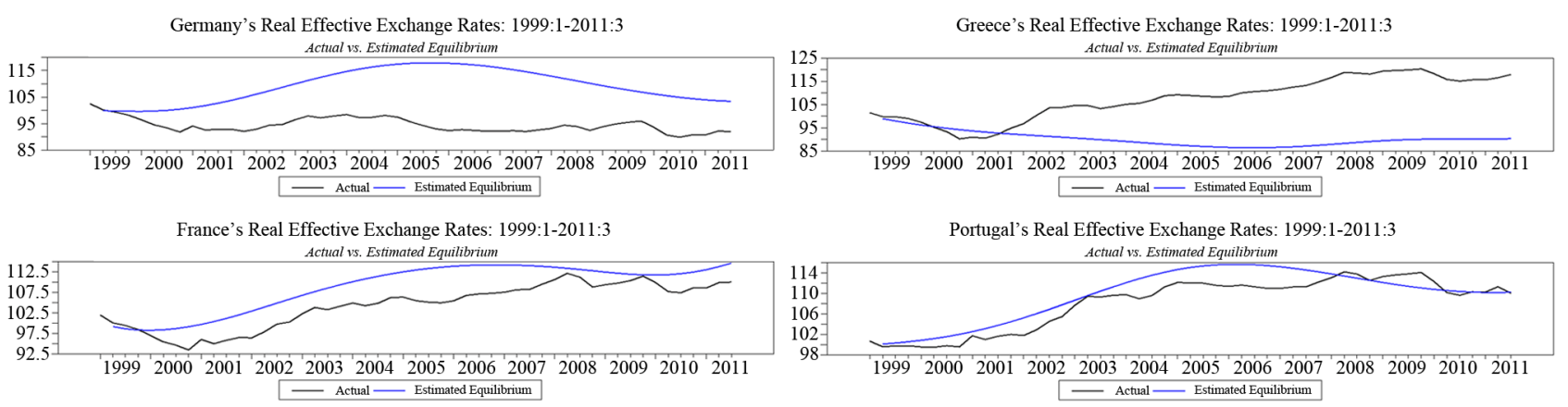

Spain's Real Effective Exchange Rates: 1999:1-2011:3
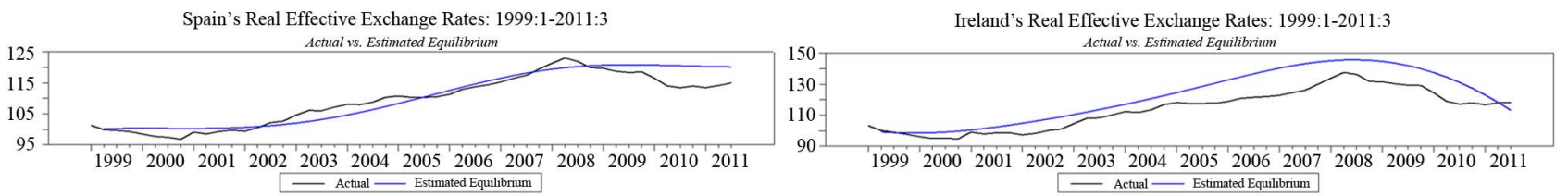

Italy's Real Effective Exchange Rates: 1999:1-2011:3

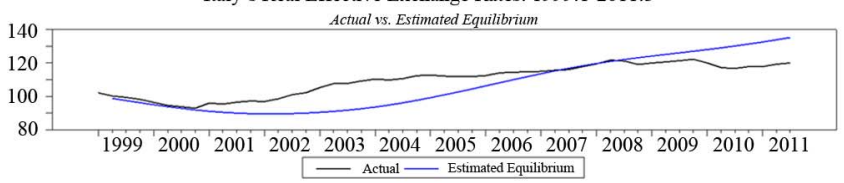

Figure 2. Real effective exchange rates: actual and equilibrium for individual countries. 

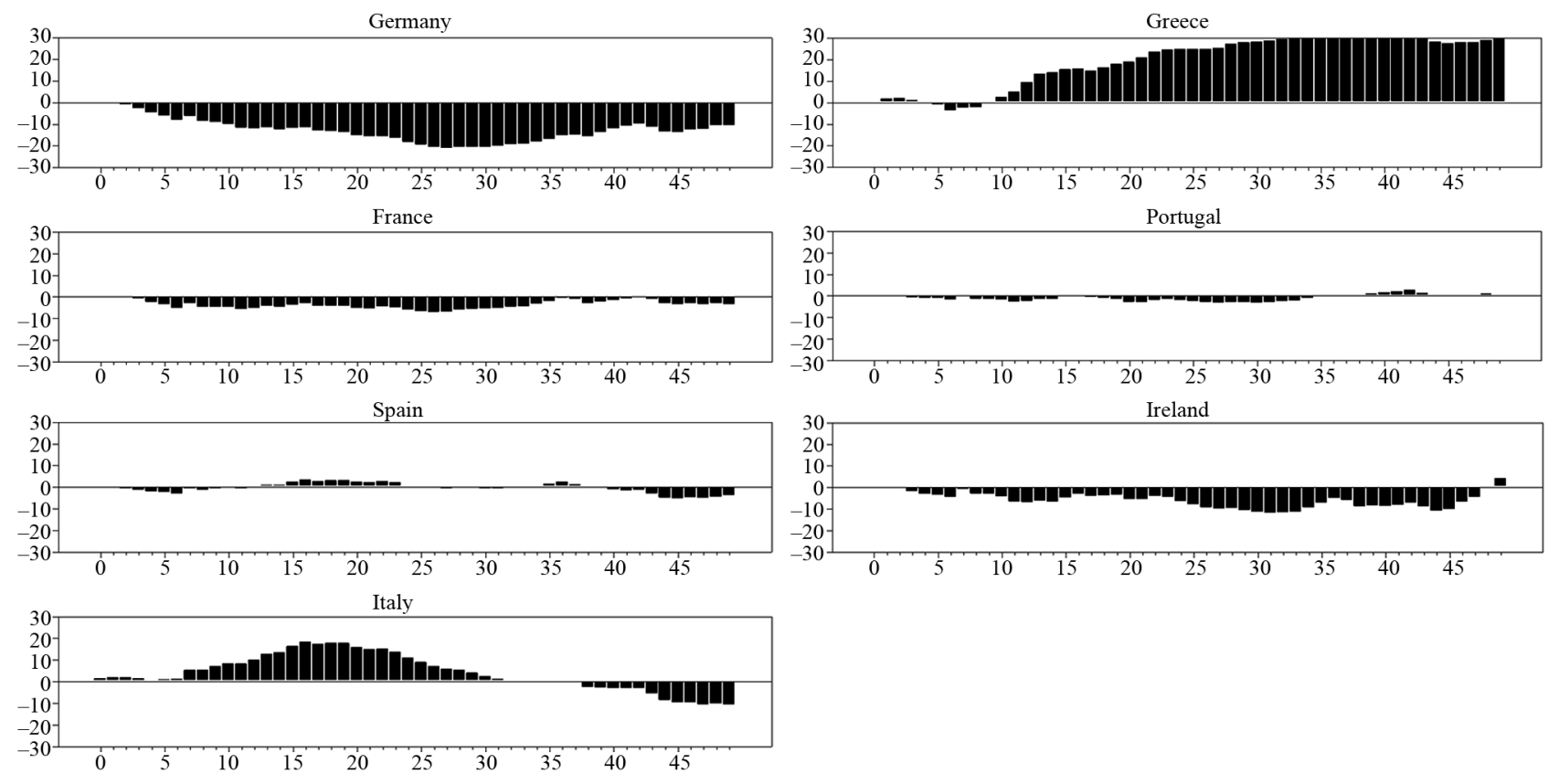

Figure 3. Overvaluation (+) and undervaluation (-) of real effective exchange rates.

These results indicate that relative to their long run BEER equilibrium values the REER for Greece is significantly overvalued, whereas the REER for Germany is noticeably undervalued.

Other countries are close to their estimated BEER equilibria, albeit with a slight tendency for undervaluation for France and Ireland. Italy went from overvaluation to undervaluation, the dynamics which may be helpful in ongoing difficulties. The REERs for Spain and Portugal are basically at their BEER long term equilibrium throughout.

\section{Conclusions}

The results represented in Table 1 and Figures 1-3 are somewhat surprising. Whereas they do indicate an increased divergence between the analyzed countries, especially between the "Southern 5" and Germany, for the 5 countries (Italy, Spain, Ireland, Portugal, France) no significant disequilibria can be identified when the BEER equilibrium concept is used.

Comparing the actual national REERs to national equilibria (Figure 3), we see clear divergence only for Germany (Undervaluation) and Greece (overvaluation).

In this context a simple thought experiment can be illuminating. Assuming that unit labor costs change only slowly over time and the nominal REER can be approximated by USD/EURO rate (on average $\$ 1.30$ per euro at the time of writing), then observed German 20\% - 25\% undervaluation would imply the "nominal equilibrium exchange rate about $\$ 1.60$ per Euro. On the other side the observed about $30 \%$ overvaluation for Greece (relative to the calculated BEER equilibrium) would imply the nominal exchange rate $\$ 1.0$ per Euro.

One may see the calculations in the previous paragraph as the "justification" for demands of the so called "Troika" for Greece to reduce radically their unit labor costs. (Reportedly requiring the reduction in private sector wages and benefits by the combined amount about 30\%). The "internal devaluation" at work!

However, one should caution that BEER estimates are based on the assumption of the existing economic policies and dynamics, albeit smoothed out by eliminating temporary shocks and other short term phenomena. It is therefore not surprising that the actual and the "estimated equilibrium" REERs often come relatively close together. Hence, only a significant and protracted deviation from the estimated equilibrium will be observed. In other words, it is recognized that the methodology employed in this analysis may be implicitly biased toward the equilibrium and hence to underestimate the extent of the actual competitiveness problem inherent in the Eurozone construction and policies.

Nevertheless the competitiveness problem within the Eurozone clearly exists. Whether the solution is in the Eurozone's restructuring, "internal devaluation" in some countries (which is the actual, even if unspoken, rationale behind the austerity programs in the "southern tier" countries (plus Ireland)) or some combination of both remains to be seen. But, clearly, the current situation is unsustainable and has to be addressed.

\section{REFERENCES}

[1] S. Tilford, "Will the Eurozone Crack?" Center for Euro- 
pean Reform, London, September 2006.

[2] J. Baffes, I. A. Elbadawi and S. A. O'Connell, "Single Equation Estimation of the Equilibrium Real Exchange Rate," Policy Research Working Paper 1800, The World Bank, Washington DC, August 1997.

[3] T. Bayoumi, H. Faruqee and J. Lee, "A Fair Exchange? Theory and Practice of Calculating Equilibrium Exchange Rates," IMF Working Paper WP/05/229, International Monetary Fund, Washington DC, December 2005.

[4] W. R. Cline and J. Williamson, "Estimates of Fundamental Equilibrium Exchange Rates," Policy Brief PB11-5, Peterson Institute of International Economics, Washington DC, May 2011.

[5] T. Feyzioglu, "Estimating the Equilibrium Real Exchange Rate: An application to Finland," IMF Working Paper WP/97/109, International Monetary Fund, Washington DC, September 1997.

[6] S. Wren-Lewis, "Estimates of Equilibrium Exchange Rates for Sterling against the Euro," HM Treasury Printing Office, London, 2003

[7] R. Y. Siregar and R. Rajan, "Model of Equilibrium Real Exchange Rates Revisited: A Selective Review of the Literature," Discussion Paper No. 0604, Centre for International Economic Studies, University of Adelaide, Adelaide, 2006.

[8] J. Stein, "The Natural Real Exchange Rate of the US Dollar and Determinants of Capital Flows," In: J. Williamson, Ed., Estimating Equilibrium Exchange Rates, Institute of International Economics, Washington DC, 1994, pp. 133176.

[9] G. Gandolfo and A. Felettigh, "The NATREX: An Alternative Approach. Theory and Empirical Verifications," Working Paper No. 52, University "La Sapienza", Rome, 1998.

[10] J. Stein, "The Evolution of the Real Value of the US Dollar Relative to the G7 Currencies," In R. MacDonald and J. Stein, Eds., Equilibrium Exchange Rates, Kluwer Academic Publishers, Amsterdam, 1999, pp. 67-102. doi:10.1007/978-94-011-4411-7_3

[11] P. B. Clark and R. MacDonald, "Exchange Rates and Economic Fundamentals: A Methodological Comparison of BEER's and FEER's," IMF Working Paper WP/98/67,
International Monetary Fund, Washington DC, May 1998.

[12] A. Bouveret, "BEER Hunter: The Use and Misuse of Behavioral Equilibrium Exchange Rates", Mimeo, Observatoire Français des Conjonctures Economiques, Paris, April 2010.

[13] P. B. Clark and R. MacDonald, "Filtering the BEER: A Permanent and Transitory Decomposition," IMF Working Paper WP/00/144, International Monetary Fund, Washington DC, August 2000.

[14] P. Dias and R. MacDonald, "BEER Estimates and Target Current Account Imbalances," Mimeo, Peterson Institute of International Economics, Washington DC, March 2007.

[15] N. Giannellis and M. Koukouritakis, "Behavioral Equilibrium Exchange Rate and Total Misallignment: Evidence from the Euro Exchange Rate," Empirica, Vol. 38, No. 4, 2011, pp. 555-578. doi:10.1007/s10663-010-9146-Z

[16] R. MacDonald, "What Determines Real Exchange Rates? The Long and Short of It," Journal of International Financial Markets, Institutions and Money, Vol. 8, No. 2, 1997, pp. 117-153. doi:10.1016/S1042-4431(98)00028-6

[17] R. MacDonald, "Exchange Rates: Do Fundamentals Matter?" Economic Journal, Vol. 109, No. 459, 1999, pp. F673-F691. doi:10.1111/1468-0297.00479

[18] R. MacDonald, "Concepts to Calculate Equilibrium Exchange Rates: An Overview," Discussion Paper 300, Economic Research Group of the Deutsche Bundesbank, Frankfurt, July 2000.

[19] F. Maeso-Fernandez, C. Osbat and B. Snatz, "Determinants of the Euro Real Effective Exchange Rate," Working Paper No. 85, European Central Bank, Frankfurt, November 2001.

[20] C. Osbat, R. Rueffer and B. Schnatz, "The Rise of the Yen Vis a Vis the ('Synthetic') Euro: Is It Supported by Economic Fundamentals?” Working Paper No. 224, European Central Bank, Frankfurt, April 2003.

[21] J. Frenkel and M. Mussa, "Asset Markets, Exchange Rates and the Balance of Payments," In: E. Grossman and K. Rogoff, Eds., Handbook of International Economics, Vol. 2, North Holland, Amsterdam, 1986, pp. 679-747. 